\title{
SELO DE QUALIDADE PRÓPRIO COMO ESTRATÉGIA PARA MUDANÇA DE CULTURA E IMPLEMENTAÇÃO DE MÉTODO DE AVALIAÇÃO DA QUALIDADE
}

Helaine Carneiro Capucho Lorena Bezerra Carvalho Marcia Amaral Dal Sasso Bruna Mafra Guedes Leili Mara Mateus da Cunha 


\section{OBJETIVO}

Descrever o processo de criação de um selo próprio de qualidade em uma rede de 40 hospitais universitários brasileiros, que possui mais de 53 mil colaboradores e 9 mil leitos ativos. 


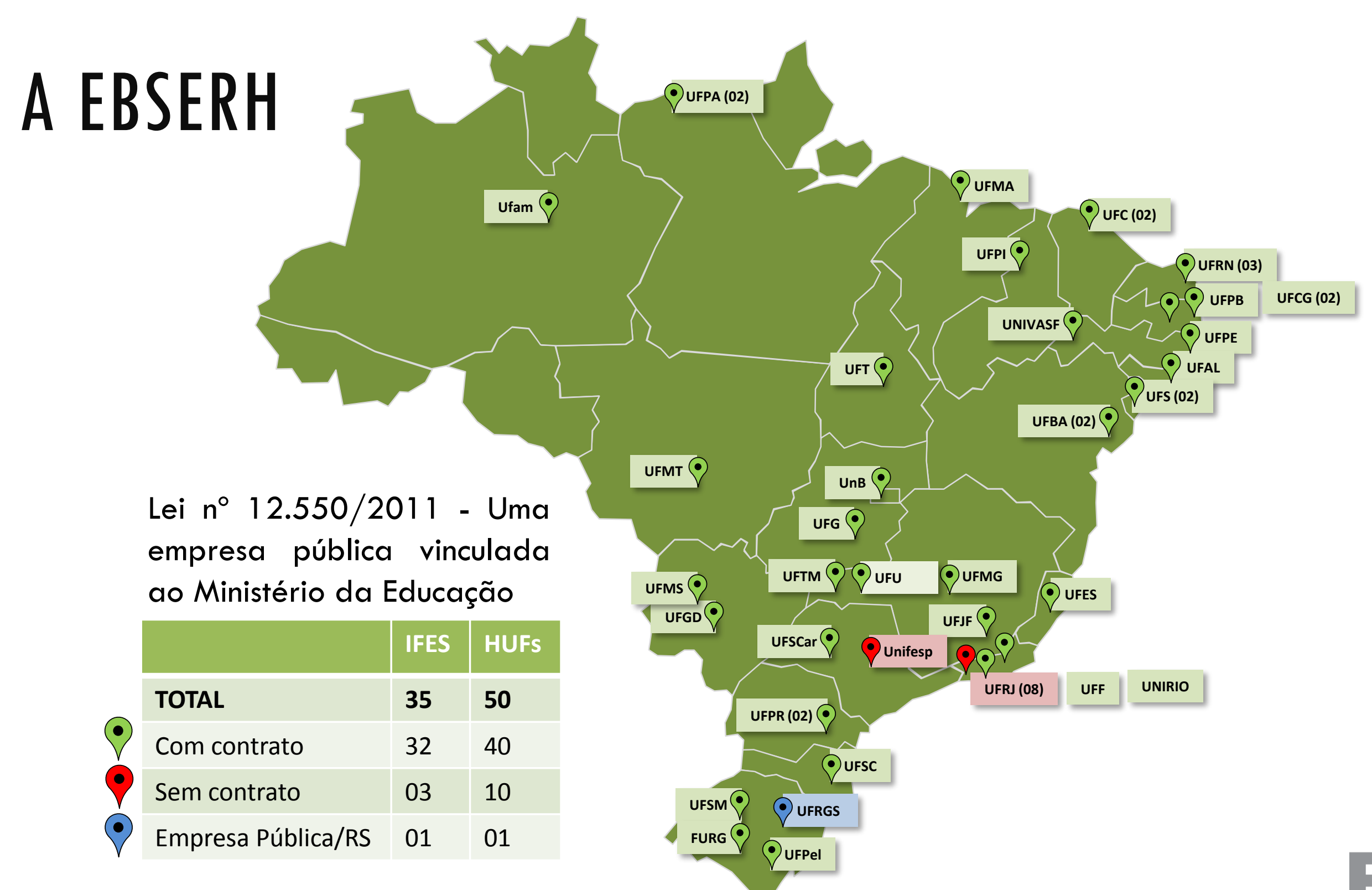

Quali : $\mathfrak{D}$

Lei $n^{\circ} 12.550 / 2011$ - Uma empresa pública vinculada ao Ministério da Educação

\begin{tabular}{|l|l|l|}
\hline Com contrato & 32 & 40 \\
\hline Sem contrato & 03 & 10 \\
\hline Empresa Pública/RS & 01 & 01 \\
\hline
\end{tabular}




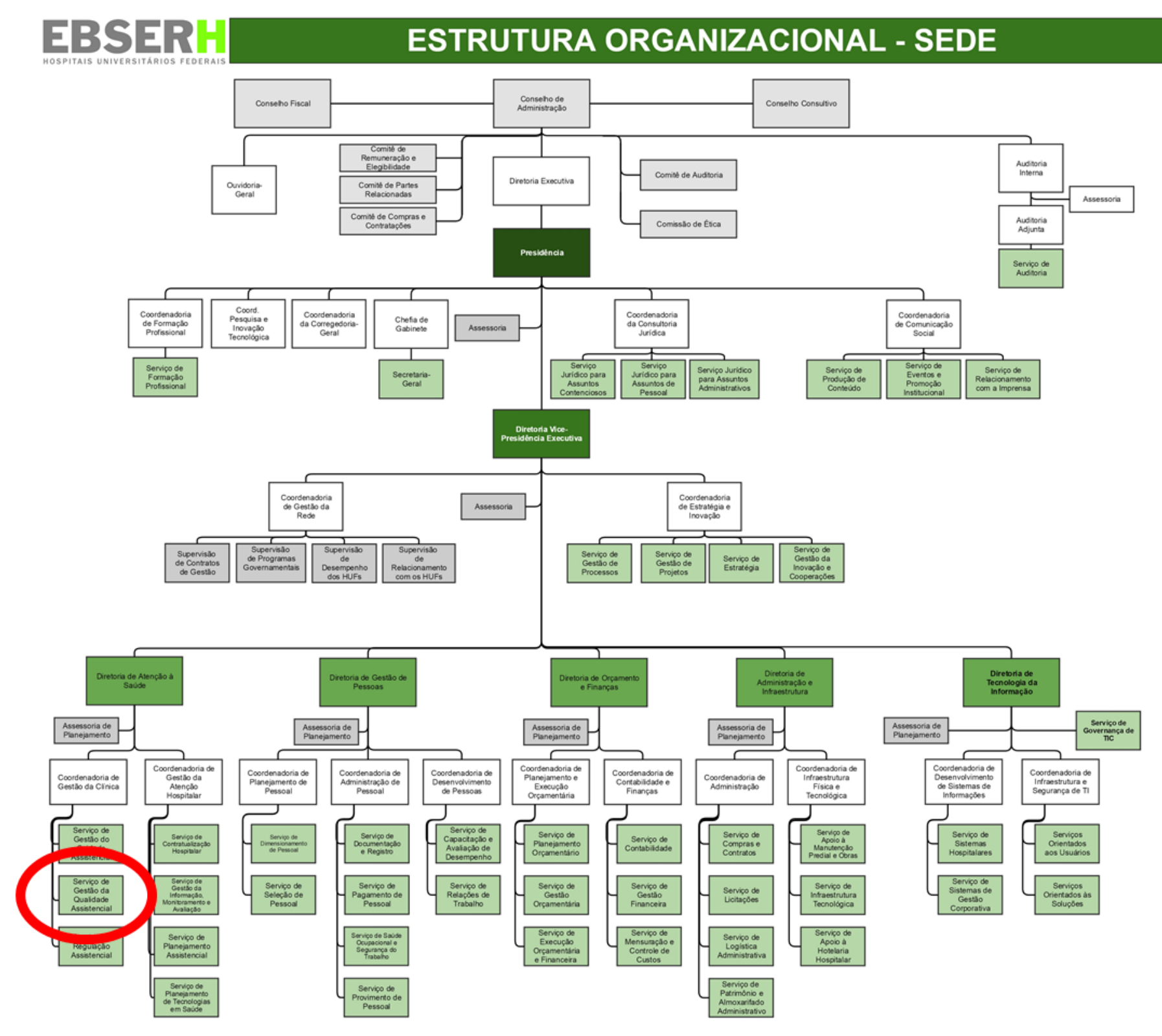




\section{RESULTADOS Mapa estratégico da Ebserh 2018-2022}

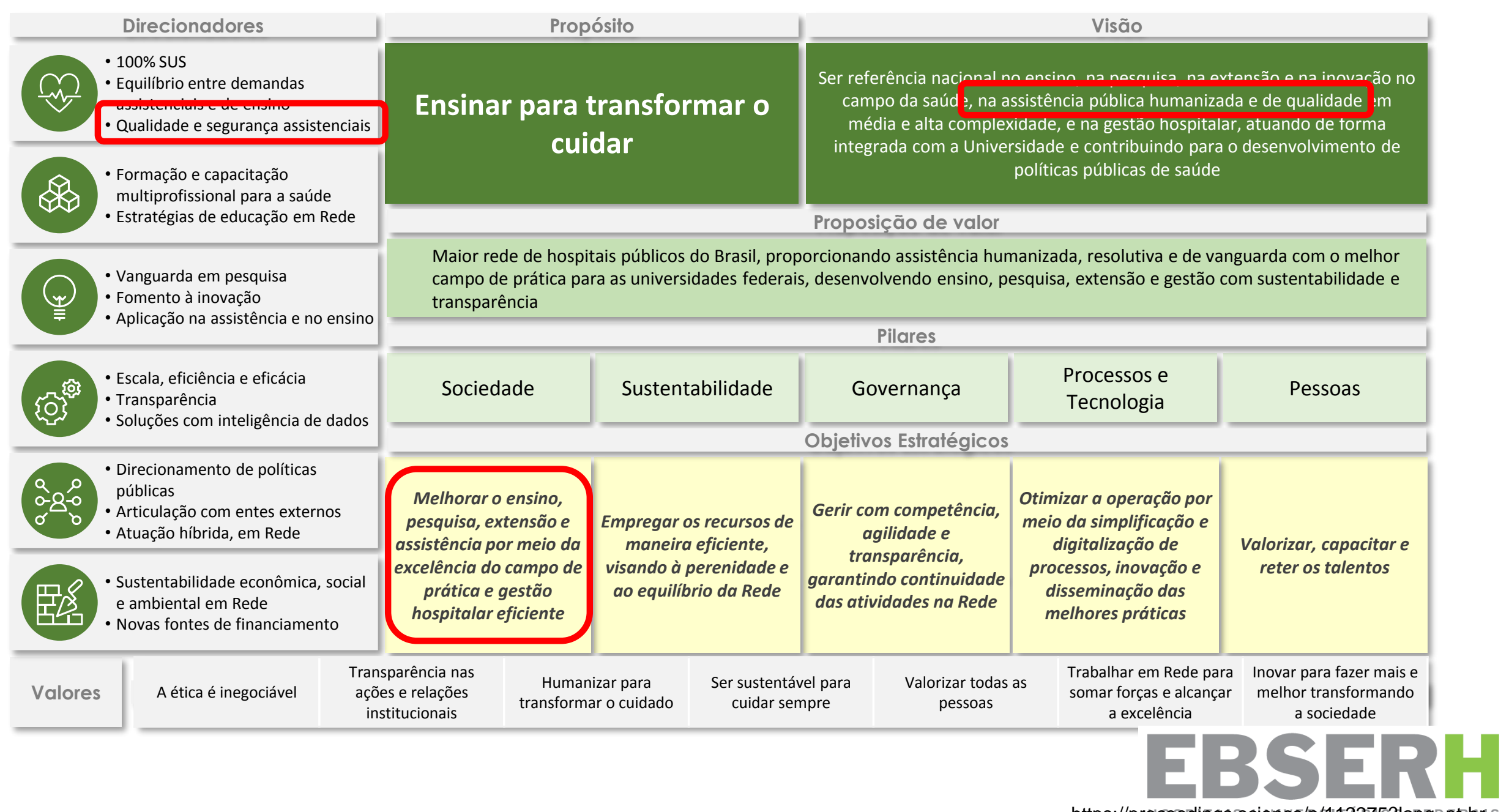




\section{RESULTADOS}

\section{PLANEJAMENTO ESTRATÉGICO DA EBSERH 2018-2022}

Iniciativas Estratégicas por diretoria

\begin{tabular}{|c|c|}
\hline Diretoria de Atenção à Saúde & Ensino, Pesquisa e Inovação* \\
\hline 1.01 Implantação da certificação Rede Ebserh de qualidade & 1.04 Fortalecimento do campo de prática \\
\hline 1.03 Atuação propositiva na formulação de políticas públicas & $\begin{array}{l}1.05 \text { Implantação de programa de divulgação da produção } \\
\text { cientifica }\end{array}$ \\
\hline $\begin{array}{l}2.07 \text { Implantação do programa nacional de diretrizes de } \\
\text { contratualização de HUFs }\end{array}$ & $\begin{array}{l}2.03 \text { Definição do modelo de captação de recursos para } \\
\text { ensino e pesquisa }\end{array}$ \\
\hline 4.01 Implantação de modelo de gestão da atenção & 2.04 Fortalecimento da Avaliação de Tecnologias em Saúde \\
\hline Diretoria de Orçamento e Finanças & $\begin{array}{l}3.03 \text { Modelo institucional de ensino, pesquisa, inovação e } \\
\text { extensão }\end{array}$ \\
\hline $\begin{array}{l}2.01 \text { Implantação de Modelo de Custos } \\
2.02 \text { Implantação de Orçamento Base Zero }\end{array}$ & $\begin{array}{l}3.04 \text { Fortalecer os modelos de pesquisa em Rede } \\
4.05 \text { Apoio a certificação e recertificação de hospitais de } \\
\text { ensino }\end{array}$ \\
\hline Diretoria de Gestão de Processos de TI & $\begin{array}{l}4.06 \text { Programa de fortalecimento das residências } \\
5.05 \text { Instituição de plano de difusão de conhecimento para } \\
\text { Rede Ebserh }\end{array}$ \\
\hline $\begin{array}{l}4.07 \text { Estratégia de arquitetura de tecnologia } \\
4.08 \text { Evoluşãa da arquitetura técnica de TT } \\
4.09 \text { Implementação de metodologias ágeis para } \\
\text { desenvolvimento de TI }\end{array}$ & 5.06 Elaboração de modelo de incentivo ao pesquisador \\
\hline $\begin{array}{l}\text { 4.10 Avaliação do portfólio de sistemas } \\
\text { 4.11 Avaliação do sistema assistencial }\end{array}$ & Diretoria de Administração e Infraestrutura \\
\hline $\begin{array}{l}\text { 4.12 Estratégia de infraestrutura de TI } \\
4.13 \text { Estratégia e Modelo de Inteligência da Informação } \\
4.14 \text { Estratégia de risco e segurança da informação } \\
4.15 \text { Estratégia de transformação digital }\end{array}$ & $\begin{array}{l}2.06 \text { Implementar modelo de compras da Rede } \\
4.03 \text { Elaboração de plano de gerenciamento de } \\
\text { infraestrutura para hospitais escola }\end{array}$ \\
\hline
\end{tabular}

Diretoria Vice Presidência Executiva

2.08 Estruturação do centro de serviços compartilihados 3.01 Implantação de modelo de gestão da Rede a partir do Mapa de Fortalezas

3.02 Implantação estrutura organizacional orientada a

serviços

4.02 Implantação de modelo de fluxo de informação na

\section{Diretoria de Gestão de Pessoas}

2.05 Redimensionamento do quadro de Pessoal dos HUFs Sede

4.04 Otimizar processo de dimensionamento: quadro $\mathrm{de}$ pessoal HUFs

5.01 Implantação do Modelo de atração e seleção 5.02 Implantą̧ão do modelo de carreiras, incentivo e gestão de desempenho

5.03 Implantação do Modelo de qualificação e capacitação 5.04 Implantą̧ão do Modelo de gestão de pagamento de horas extras e adicionais 


\section{RESULTADOS Minuta do Manual}

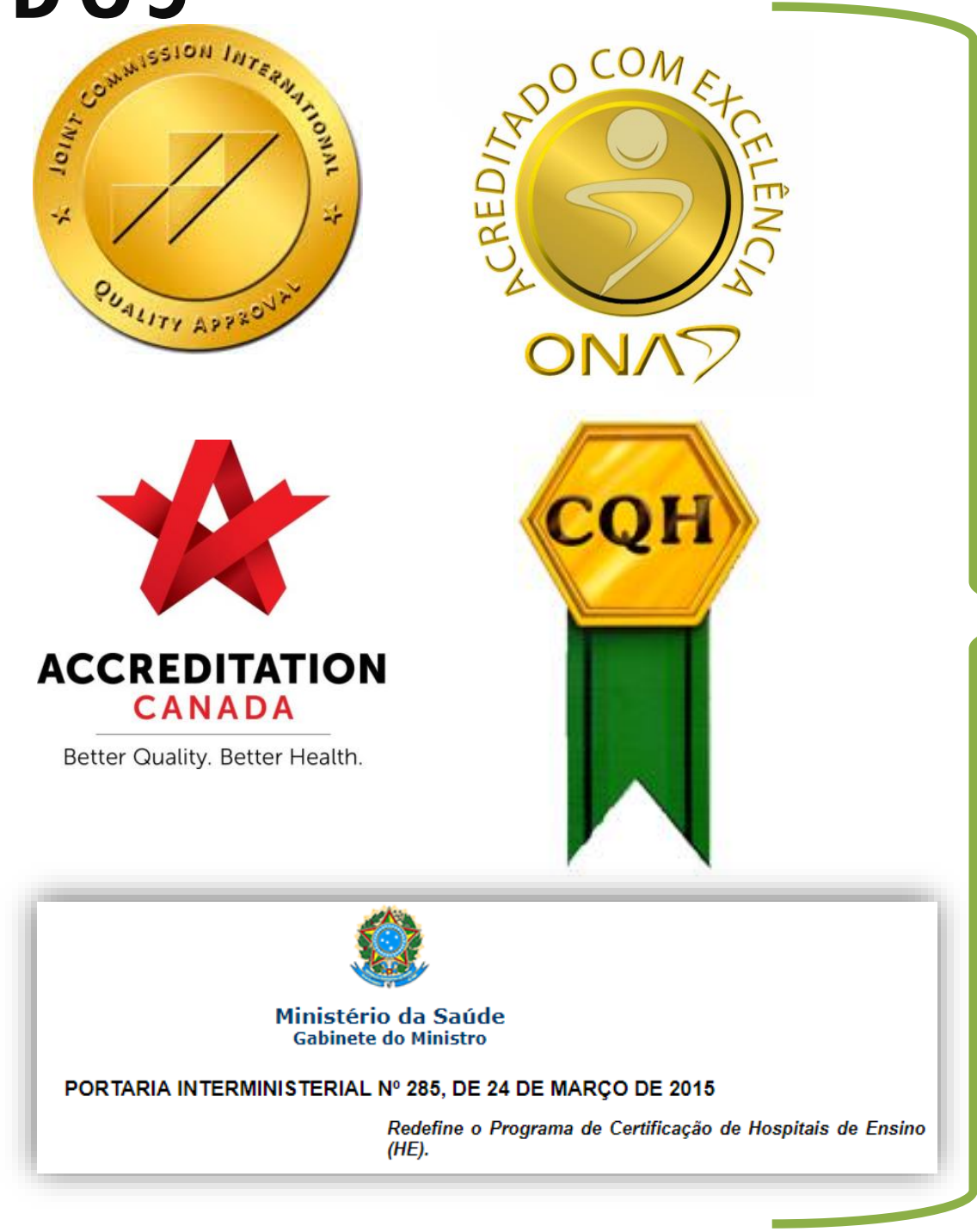

SELO EBSERH DE QUALIDADE

Hanual de diretrizes e requisitos

12 ediç̃o
2013

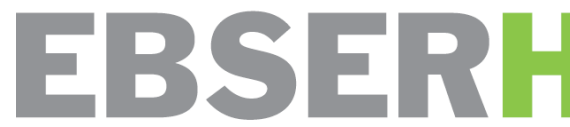




\section{RESULTADOS}

A. PROCESSOS FINALÍSTICOS

\section{Ensino, Pesquisa, Extensão e Inovação em Saúde}

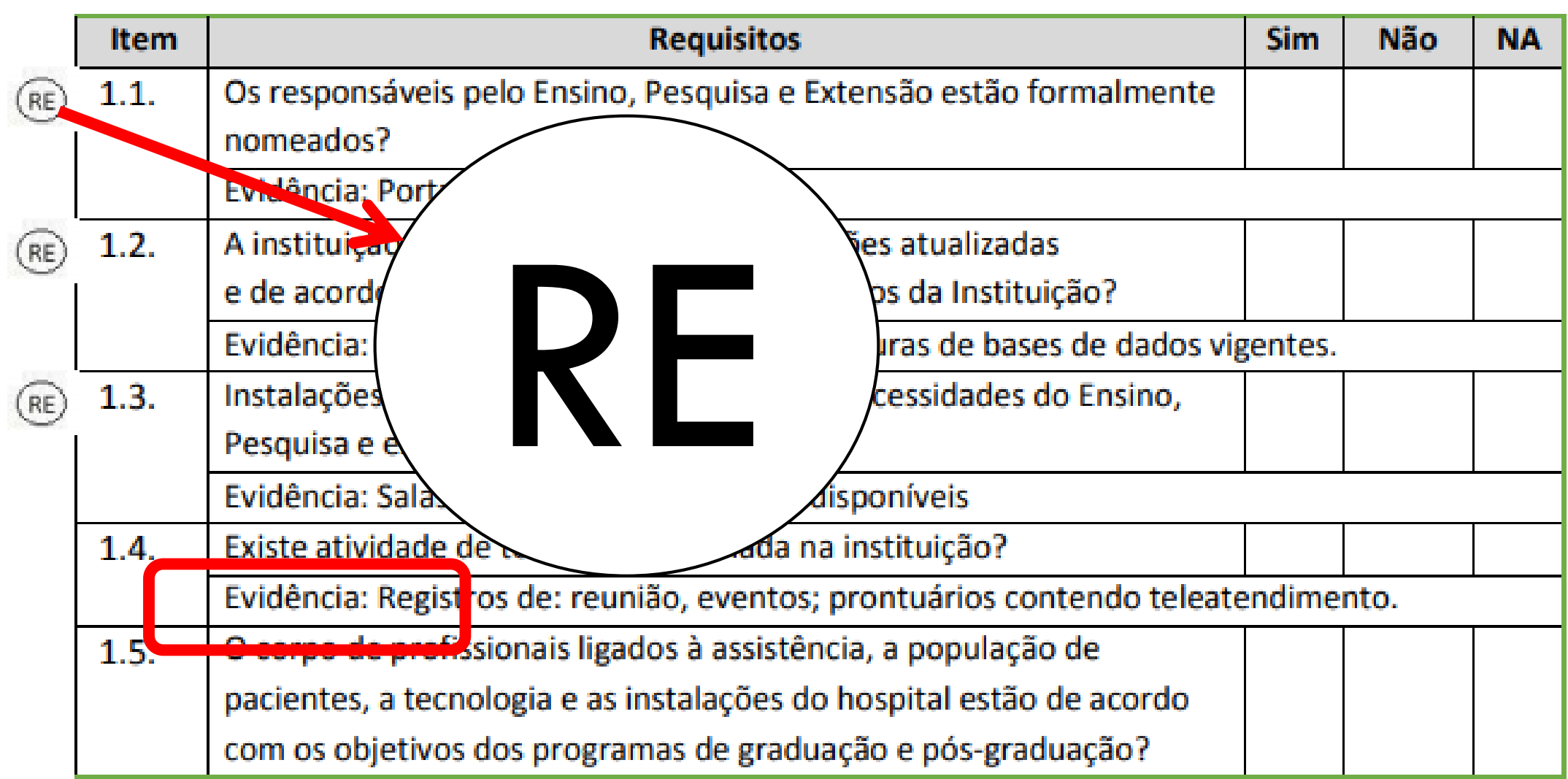

Página $\mathbf{2 8}$ de $\mathbf{1 5 8}$ 


\section{RESULTADOS}
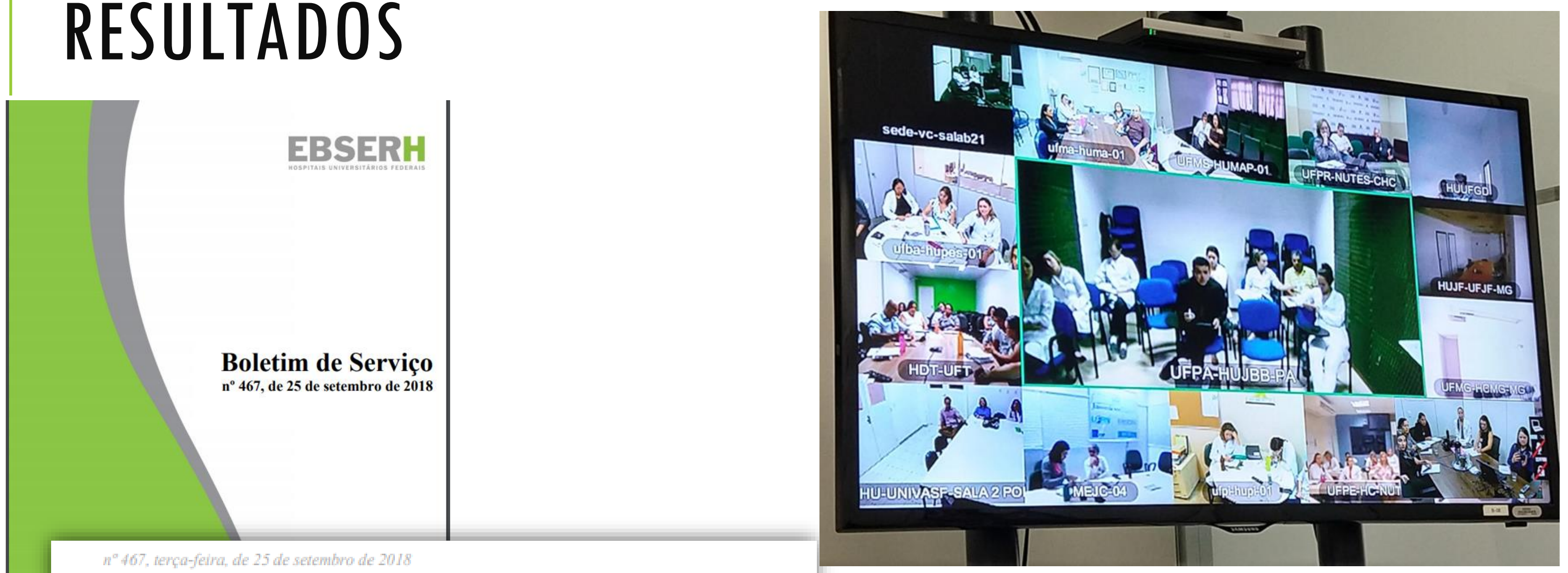

DIRETORIA DE ATENÇÃo A SAÚdE

\section{CONSULTA PÚBLICA}


Portaria-SEI n ${ }^{\circ}$ 23, de 05 de novembro de 2018

O Diretor de Atenção à Saúde da Empresa Brasileira de Serviços Hospitalares - Ebserh, no uso das atribuições que lhe são conferidas pelo artigo 52 do Regimento Interno, cuja revisão foi aprovada pela Resolução do Conselho de Administração n ${ }^{\circ}$ 54, de 10 de maio de 2016, publicada no DOU de 16 de maio de 2016,

Instituir o Programa Ebserh de Gestão da Qualidade e o Selo Ebserh de Qualidade SEQuali, com o objetivo de promover a gestão da qualidade, a excelência na gestão, na educação, na pesquisa e na extensão em saúde no âmbito dos hospitais universitários federais (HUF) que compõem a rede Ebserh. 


\section{RESULTADOS}

O Programa Ebserh de Gestão da Qualidade consiste em um sistema próprio de avaliação periódica que tem como objetivo promover a cultura de melhoria contínua dos serviços prestados à população brasileira pelos hospitais da rede Ebserh nas áreas assistencial, no ensino, na pesquisa, na inovação e na extensão em saúde.

O Selo Ebserh de Qualidade visa reconhecer formalmente os hospitais que atingirem padrões estabelecidos no sistema de avaliação. 


\section{RESULTADOS}

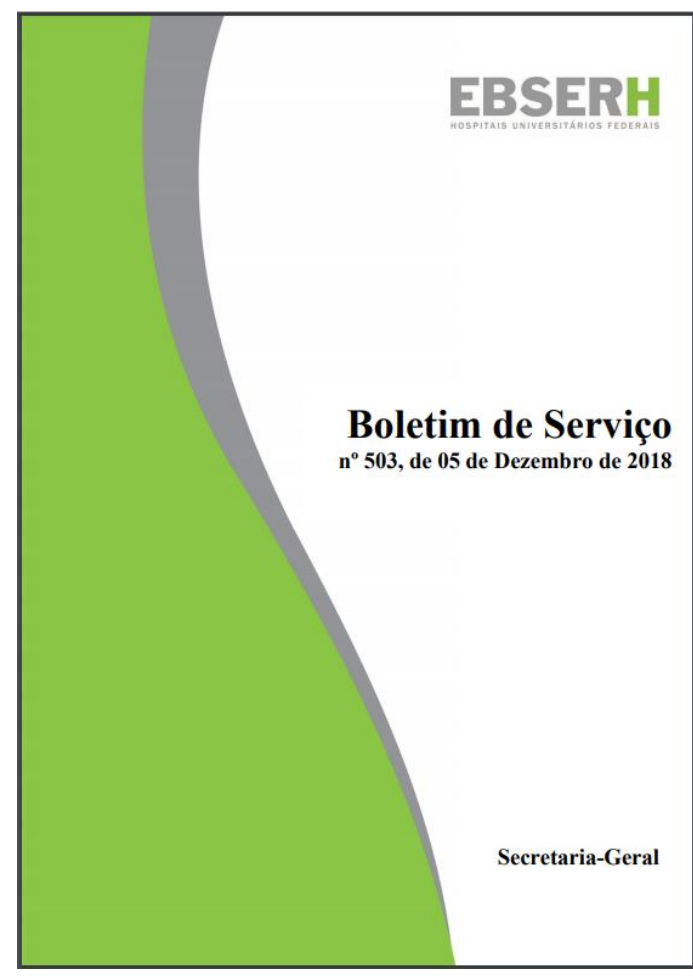

Portaria-SEI no 26, de 04 de dezembro de 2018

Estabelece as competências dos Setores de Gestão da Qualidade e Vigilância em Saúde dos hospitais, anteriormente denominados Setores de Vigilância em Saúde e Segurança do Paciente 


\section{RESULTADOS}

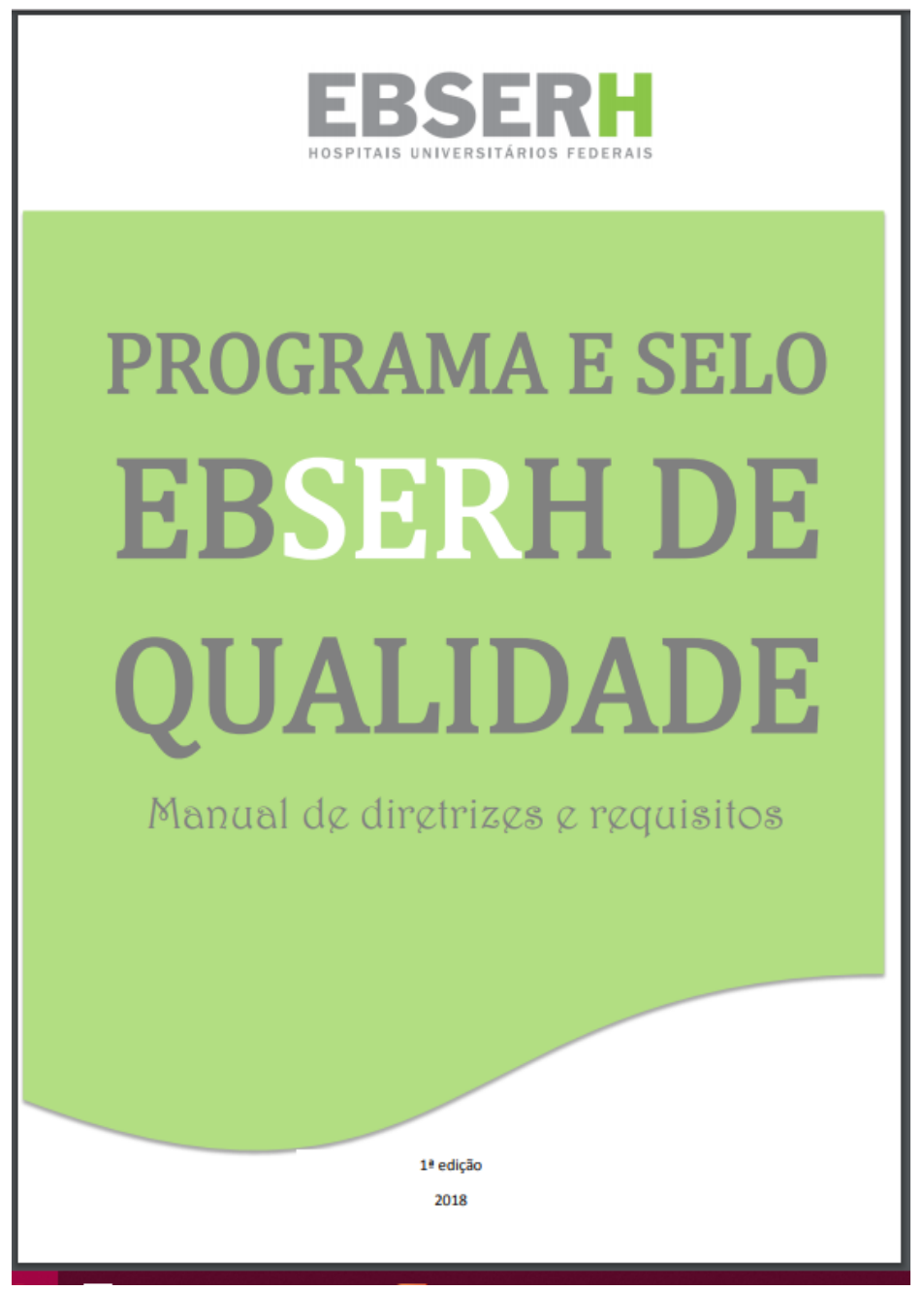

Portaria-SEI no 26, de 04 de dezembro de 2018

Aprova os documentos norteadores do Programa Ebserh de Gestão da Qualidade e o Selo Ebserh de Qualidade 


\section{CONCLUSÕES próxinos passos}

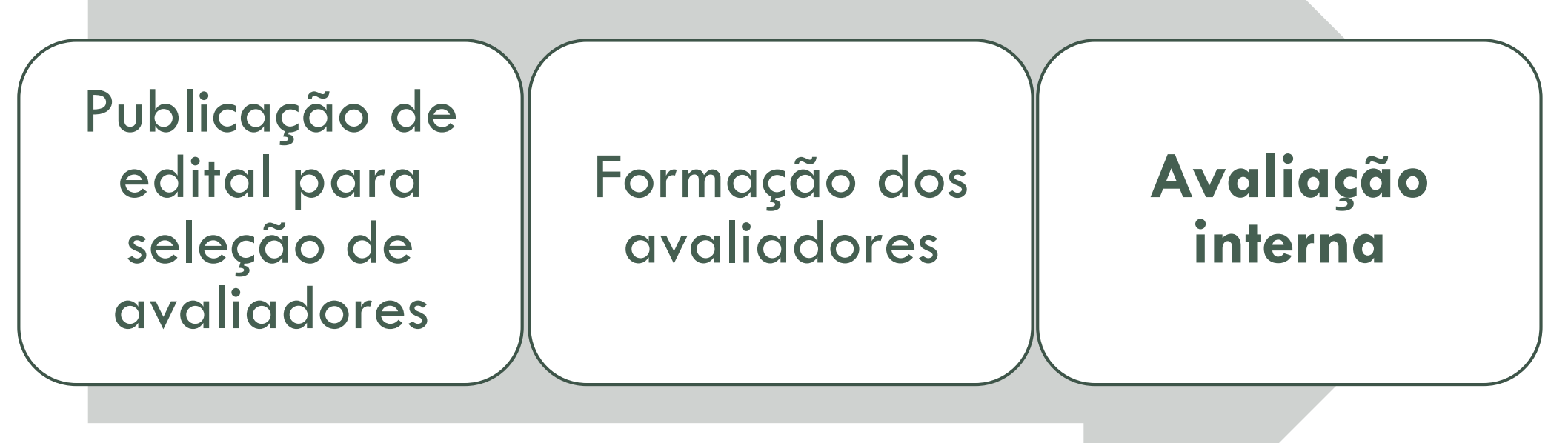


Comece fazendo o que é necessário, depois o que é possível, e de repente você estará fazendo o impossível.

São Francisco de Assis

OBRIGADA! helaine.capucho@unb.br 